Research Article

\title{
Study on Effects of External Water Amount on Organic Intercalation of Montmorillonite and Its Mechanism
}

\author{
Limei Wu $(\mathbb{D}$, Yongbin Wang, Lu Yang, Qing Wang $(\mathbb{D}$, and Changwei Xu \\ School of Materials Science and Engineering, Shenyang Jianzhu University, Shenyang 110168, China \\ Correspondence should be addressed to Limei Wu; lmwu@sjzu.edu.cn
}

Received 14 December 2018; Accepted 7 February 2019; Published 3 March 2019

Academic Editor: Zhiping Luo

Copyright (C) 2019 Limei Wu et al. This is an open access article distributed under the Creative Commons Attribution License, which permits unrestricted use, distribution, and reproduction in any medium, provided the original work is properly cited.

\begin{abstract}
As an important clay mineral, montmorillonite (MMT) plays a pivotal role in various fields. Water has significant effects on the organification process of MMT, which is associated with the adsorption of organic matter onto MMT with different water contents. In this study, the influence of external water content on the organic intercalation of MMT and its mechanism are discussed from both experimental and simulation results. These results reveal that as the external water content increases, the interlayer spacing of organic MMT increases first and then decreases, while the degree of organification becomes increasingly stronger. Although the interlayer spacing of the organic MMT is the largest when the external water amount is relatively small (e.g., 10\%), the molecular arrangement is disorderly and uneven, resulting in a low degree of organification. Increasing the external water content results in a more regular molecular arrangement, more compact intermolecular agglomerates, and a higher degree of order. Therefore, the addition of water plays a crucial role in the organification process of MMT, and the appropriate manufacturing technology should be selected according to the application field. The results of this study provide theoretical support for the preparation of organic MMT and also offer insight into the mechanism of organic intercalation.
\end{abstract}

\section{Introduction}

MMT is an important layered silicate mineral, and its basic structural unit is a typical 2:1 structure that is composed of a layer of aluminum oxide octahedron sandwiched between two layers of silica tetrahedra with layers bonded together by shared oxygen atoms. $\mathrm{Al}^{3+}$ in the MMT octahedral voids is usually replaced by $\mathrm{Mg}^{2+}$ and $\mathrm{Fe}^{2+}$, whereas $\mathrm{Si}^{4+}$ in the tetrahedral voids is often replaced by $\mathrm{Al}^{3+}[1,2]$. Due to the substitution of low-valence cations for high-valence cations, the structural layer produces extra negative charges. To maintain electrical neutrality, in addition to water molecules, cations with a relatively large radius (such as $\mathrm{Na}^{+}$, $\mathrm{Ca}^{2+}, \mathrm{Mg}^{2+}$, etc.,) exist between the structural layers $[3,4]$. The cationic organic matter can enter the interlayer spacings of MMT via cation exchange, which forms organic MMT. The MMTs have attractive features, such as large surface area, swelling behavior, adsorption, and ion exchange properties. The MMTs have been extensively used as the host materials and in other possible applications such as catalysis, separation, delivery, and storage [5-7]. Because of their attractive properties and ability to accommodate various kinds of organic and inorganic guest species [8], the intercalated nano-sized MMT particles $(0.6-1 \mathrm{~nm}$ in width) are ideal dispersing additives for the synthesis of organicinorganic hybrid nanocomposites to enhance mechanical, thermal, and chemical stabilities. The composites have been applied into the fields of plastic, paint, petroleum engineering, and so on [8-11]. Generally, the organic modification processes for MMT are divided into three methods: the wet method, the pregel method, and the dry method $[12,13]$. A survey of the literature indicates that there are few reports about the pregel method, and wet modification is generally reported to be superior to that of dry modification [14]. However, the process of the wet modification is more complicated than that of the dry modification, which not only has a higher industrial production cost but also causes unnecessary waste and pollution to water sources. Therefore, most of the attention has been focused on the mechanochemical dry modification for MMT [15], instead of wet modification, the research of which is relatively rare and not systematic or thorough enough. 
Water molecules play an important role in the intercalation process of organic MMT. After the intercalation process, the occurrence and interaction between water molecules and the interlayer organic cations of MMT play important roles to investigate the effects that water molecules have on the intercalation process of organic matter $[16,17]$. The interlayer spacing of clay minerals can be entirely attributed to the variations in amounts of organic cations and water between layers or to the variation in thickness of the organic cation/water complexes. Therefore, water molecules not only play a role in the preliminary intercalation and ongoing intercalation process but also play important roles in the postintercalation processes. Compared to the easier study on the role of water in organic MMT after organic intercalation, it is more difficult to investigate the actions of free water in the environment and the interlayer bound water during the process of organic intercalation. So far, no detailed systematic reports have been conducted, but it is of great significance to explore the organic intercalation process of MMT.

In this study, the influencing role of external water amount on organic intercalation of MMT and its mechanism are discussed through both experiments and molecular dynamics simulations. The external water is an important driving force in the organic intercalation process for MMT. In an aqueous solution, interlayer cations like $\mathrm{Na}^{+}$can diffuse from the interlayer spacing of MMT into the aqueous solution. The loss of $\mathrm{Na}^{+}$destroys the charge balance of the MMT complex, thus leading to negative charges in the MMT layer. When this happens, the organic cations in the solution will enter the interlayer spacings due to their electrostatic attraction to the MMT layer, which will result in a gradual increase in the MMT layer spacing. Therefore, it is important to investigate the effects of external water on the organic intercalation of MMT since it plays an important role in the preparation of organic MMT and allows for an exploration into the mechanism of organic intercalation.

\section{Experiment and Methods}

2.1. Materials. The montmorillonite used was $\mathrm{SW}-2$ obtained from the Clay Mineral Repositories in Purdue University (West Lafayette, IN) and was used without further purification. It has a chemical formula of $\left(\mathrm{Ca}_{0.12} \mathrm{Na}_{0.32} \mathrm{~K}_{0.05}\right)\left[\mathrm{Al}_{3.01} \mathrm{Fe}(\mathrm{III})_{0.41}\right.$ $\left.\mathrm{Mg}_{0.54}\right]\left[\mathrm{Si}_{7.98} \mathrm{Al}_{0.02}\right] \mathrm{O}_{20}(\mathrm{OH})_{4}$, a CEC of $85 \pm 3 \mathrm{mmol}_{\mathrm{c}} / 100 \mathrm{~g}$, a layer charge of $0.32 \mathrm{eq} / \mathrm{mol}$ per $(\mathrm{Si}, \mathrm{Al})_{4} \mathrm{O}_{10}$, an external surface area (ESA) of $23 \mathrm{~m}^{2} / \mathrm{g}$, and a mean particle size of $3.2 \mu \mathrm{m}$ with a $d_{25}$ to $d_{75}$ in the range of $3-10 \mu \mathrm{m}$ [18].

1-Hexadecyl-3-methylimidazolium chloride monohydrate $\left(\mathrm{C}_{16} \mathrm{mimCl}\right.$, CAS\#: 404001-62-3) was obtained from Shanghai Darui Fine Chemical Co. Ltd. (Shanghai, China).

2.2. Experiment. $5 \mathrm{~g}$ of $\mathrm{MMT}$ and $3 \mathrm{~g}$ of 1 -hexadecyl-3methylimidazolium chloride monohydrate $\left(\mathrm{C}_{16} \mathrm{mimCl}\right)$ were mixed together, and the mixture and a grinding ball were added into the grinding tank of a ball mill according to the appropriate ratio $(1: 20)$. The organic MMT was prepared by milling at $200 \mathrm{rpm} / \mathrm{min}$ for 2 hours with different amounts of water added.
2.3. Methods. X-ray diffraction pattern of the sample was characterized with an X-ray diffractometer (XRD-6100, Shimadzu (China) Co., Ltd.); the diffraction source was a copper target $(\mathrm{Cu} \mathrm{K} \alpha)$; the tube flow was $80 \mathrm{~mA}$; the tube voltage is $60 \mathrm{kV}$, and the rotation speed was $2 \mathrm{deg} / \mathrm{min}$. The sample was placed on a horizontal table. The directional scanning process proceeded from $3^{\circ}$ to $70^{\circ}$ with the angle gradient of each scan around $0.02^{\circ}$. The change in intensity of $d_{001}$ of MMT was measured in order to estimate the intercalation effect, and the $d$ value was calculated according to the Bragg equation.

The Fourier transform infrared spectra were characterized with the FTS 2000 series model produced by Nikol, USA. The selected spectral range was $400 \mathrm{~cm}^{-1}$ to $4000 \mathrm{~cm}^{-1}$, and the resolution was $4 \mathrm{~cm}^{-1}$. The sample to be measured was mixed with $\mathrm{KBr}$ powder with the mass ratio of $1: 100$, and its spectral band was recorded.

The thixotropy was characterized by the viscosity ratio at $6 \mathrm{rmp}$ and $60 \mathrm{rmp}$, which were measured with a rotary viscometer. In this experiment, the recorded value from the viscometer after opening for 10 seconds was used as the viscosity of paint, and the shear and recovery processes were 3 minutes. The rheological curves of organic MMT were measured by a rheometer (Model No. HAAKE RotoVisco1). The test conditions were as follows: the shear rate increased from $0 s^{-1}$ to $200 s^{-1}$ and then decreased from $200 s^{-1}$ to $0 \mathrm{~s}^{-1}$, and the increasing and decreasing time were both 3 minutes at a constant temperature of $25^{\circ} \mathrm{C}$. The measured data were automatically fitted to draw a relationship curve between shear stress and shear rate using the Origin 8.0, and the thixotropic ring area between the upper and lower curves was calculated using an integral method.

The contact angle of each sample was measured using a JC2000D contact angle meter. The contact angle measuring instrument mainly measures the contact angle of liquid to solid, that is, the wettability of a liquid on a solid. The instrument can measure the contact angle of various liquids on various materials. When the droplets are placed on a solid plane, they can automatically spread over the solid surface or adopt a certain contact angle with respect to the solid surface. The image is frozen in a real-time window, and then the thumbnail is used for browsing. The best image is selected, and the contact angle is calculated by direct fitting, and the average value of the contact angle is obtained by three trials.

Molecular simulation was performed under the module 'Forcite' of Materials Studio 7.1 software to investigate the sorption sites of $\mathrm{C}_{16} \mathrm{mimCl}$ on $\mathrm{MMT}$. The resulting primitive unit cell was characterized by the parameters $a=15.540 \AA$, $b=17.940 \AA, c=12.44 \AA, \alpha=\gamma=90^{\circ}$, and $\beta=99^{\circ}$. Based on the primitive unit cell, a series of $(6 \times 4 \times 2)$ supercells were built with the spacing of layers set to $12.4 \AA$. The adsorption behavior was modeled using the universal force field. The number of cycles is 3 , and the steps of one cycle is $10^{6}$, a representative part of the interface devoid of any arbitrary boundary effects. Based on the structure of the preferential adsorption model of $\mathrm{C}_{16} \mathrm{mimCl}$ in the layer of $\mathrm{MMT}$ predicted by Monte Carlo calculation, the GGA-PW91 was used to optimize the structure again and to predict the interaction energy between $\mathrm{C}_{16} \mathrm{mimCl}$ and $\mathrm{MMT}$ layer to a greater 
accuracy. All of the GGA-PW91 calculations were performed using a double numerical plus polarization function (DNP) as basis set and DFT-D correction. So in all calculations, the heavy atoms of MMT were frozen, whereas the hydrogen of $\mathrm{MMT}$ and $\mathrm{C}_{16} \mathrm{mimCl}$ molecules was fully relaxed.

\section{Results and Discussion}

3.1. Preparation and Characterization of Organic MMT at Different Contents of External Water. The X-ray diffraction (XRD) patterns of the obtained organic MMT sample under ball milling conditions with different water contents are shown in Figure 1. No diffraction peak of $\mathrm{C}_{16} \mathrm{mimCl}$ was observed in the XRD pattern of the modified sample, indicating that $\mathrm{C}_{16} \mathrm{mimCl}$ had been inserted between the MMT layers [19]. As for the preparation process of organic MMT using the dry method, using water contents of $0 \%$ and $1 \%$, the $d_{001}$ value of the organic MMT is $2.84 \mathrm{~nm}$, and the peak shape is sharp and symmetrical, demonstrating that $\mathrm{C}_{16}$ mimCl molecules were also inserted between the MMT layers even with trace amounts of water content. With an increase in the water content, the $d_{001}$ value of organic MMT keeps increasing, resulting in the increase in the amount of $\mathrm{C}_{16} \mathrm{mimCl}$ that is inserted. Therefore, the external water played an important role in the intercalation process of the organic modifier. When the content of external water is $10 \%$, the $d_{001}$ value reaches $5.78 \mathrm{~nm}$, and the intercalated amount of $\mathrm{C}_{16} \mathrm{mimCl}$ reaches its maximum value. When the content of external water continues to increase, however, the interlayer spacing of the organic MMT decreases, and the diffraction peak of the (001) plane becomes symmetrical and sharp. When the content of external water is $30 \%$, the $d_{001}$ value of the organic MMT is $4.57 \mathrm{~nm}$. The above results indicate that the addition of external water has a great influence on the intercalation process of the organic cations. The intercalated amount of organic cations increases as more external water is added $[20,21]$, but the intercalated amount of organic cations decreases when the content of external water excesses $30 \%$.

To more fully examine the effect that the organic cations have on the MMT structure with different contents of external water [22], infrared spectrum analysis was carried out (Figure 2). The hydroxyl stretching vibration of the adsorbed water near $3436 \mathrm{~cm}^{-1}$ shifts to $3422 \mathrm{~cm}^{-1}$, and the peak intensity decreases, indicating the amount of interlayer adsorbed water decreased, and $\mathrm{C}_{16} \mathrm{mimCl}$ enters into the MMT layer [23]. Also, XRD analysis shows that the interlayer spacing increases, resulting in a decrease in peak sharpness. It is speculated that less $\mathrm{C}_{16} \mathrm{mimCl}$ entered into the interlayer spacing that had an irregular arrangement. The peaks within the range of $1000-1500 \mathrm{~cm}^{-1}$ correspond to the absorption peaks of C-H bond, wherein $1470 \mathrm{~cm}^{-1}$ is attributed to the bending vibration of $-\mathrm{CH}_{2}$ - in the molecules of organic intercalating agent $[24,25]$. The peak is sharp and the peak shape is asymmetrical, along with the higher intensity of the $-\mathrm{CH}_{2}$ - absorption peak, indicating that the $\mathrm{C}_{16}$ mimCl molecule has effectively entered into the interlayer spacing of MMT, and the intercalated amount is large. The Si-O-Si stretching vibration absorption peak of

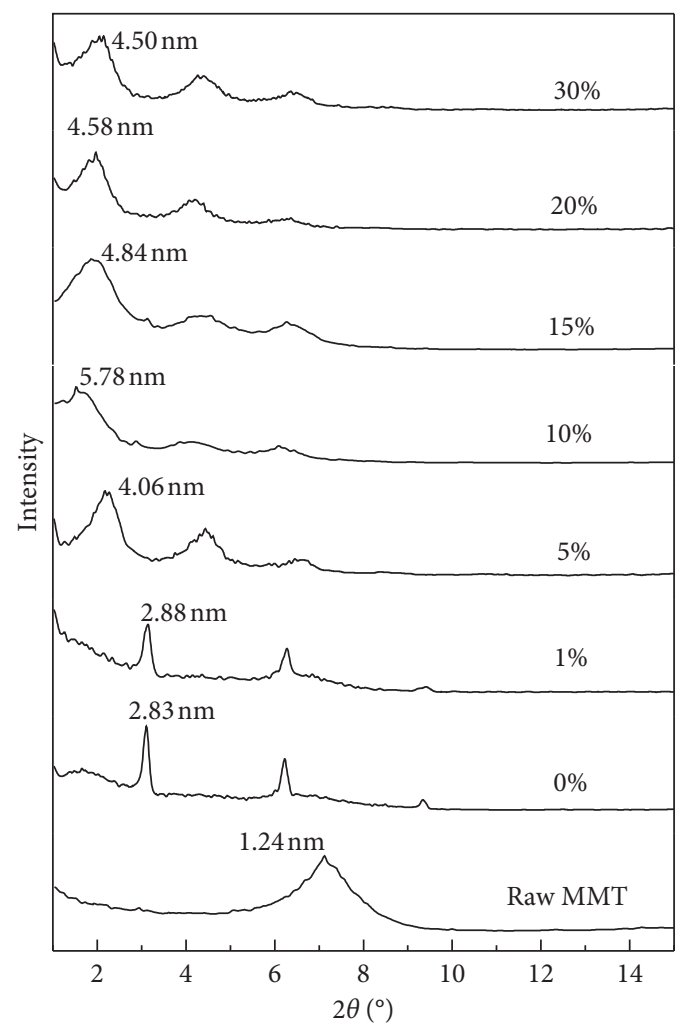

FIgUre 1: X-ray diffraction patterns of MMT and $\mathrm{C}_{16}$ mim-MMT.

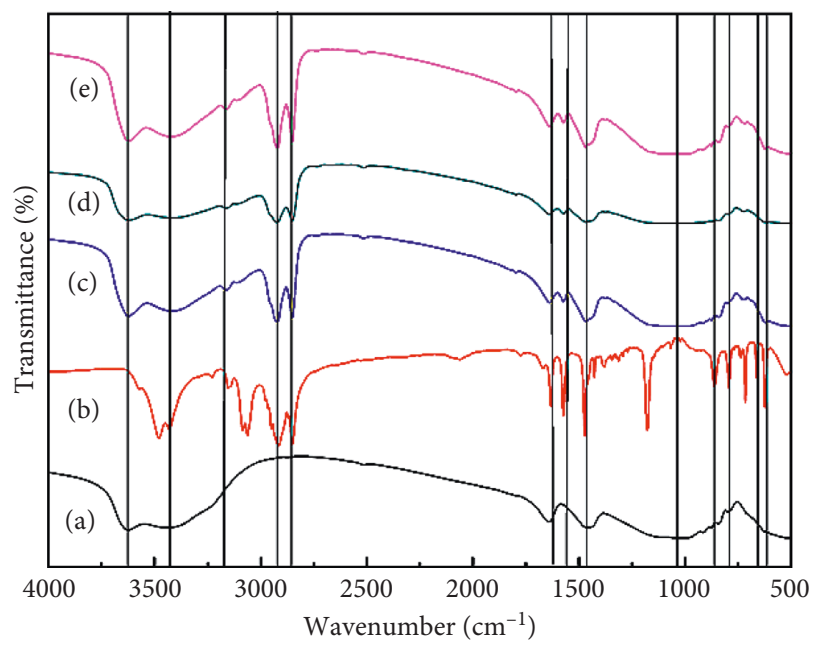

Figure 2: FTIR analyses of MMT and $\mathrm{C}_{16}$ mim-MMT. (a) MMT, (b) $\mathrm{C}_{16} \mathrm{mimCl}$, (c) $30 \%$, (d) $10 \%$, and (e) $0 \%$.

MMT at $1035 \mathrm{~cm}^{-1}$ shifted to a lower wavenumber, which may be caused by the $\mathrm{C}_{16} \mathrm{mimCl}$ coating $[26,27]$.

The content of external water affects both the preparation and the performance of organic MMT. The results of contact angle and viscosity measurements of the organic MMT prepared with different external water contents are shown in Table 1 . When the content of added water is $0 \%$, the obtained organic MMT has a contact angle of $41^{\circ}$ (Figure 3) and the viscosity cannot be measured by instrument. When the water content is $1 \%$, the contact angle of 
TABLE 1: Organic properties of MMT and $\mathrm{C}_{16}$ mim-MMT.

\begin{tabular}{lccc}
\hline Name & Contact angle $\left(^{\circ}\right)$ & Viscosity $(\mathrm{mPa} \cdot \mathrm{s})$ & $d_{(001)}(\mathrm{nm})$ \\
\hline MMT & 32 & - & 1.24 \\
$0 \%$ & 41 & - & 2.83 \\
$1 \%$ & 41 & 13.81 & 2.88 \\
$5 \%$ & 44 & 19.29 & 4.06 \\
$10 \%$ & 63 & 68.44 & 5.78 \\
$15 \%$ & 68 & 83.26 & 4.84 \\
$20 \%$ & 75 & 105.37 & 4.58 \\
$30 \%$ & 81.5 & 151.98 & 4.50 \\
\hline
\end{tabular}

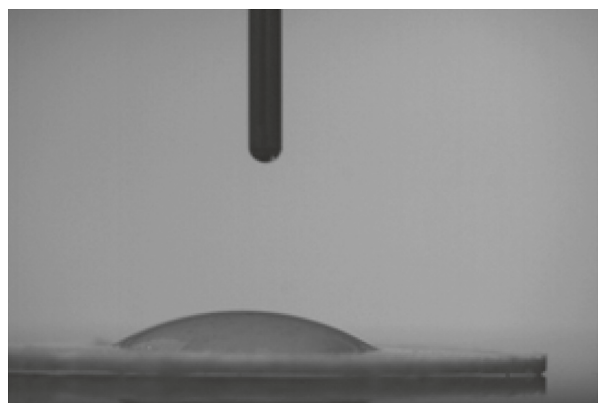

(a)

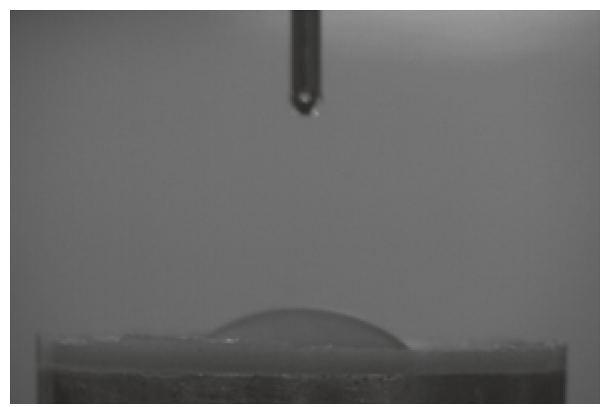

(c)

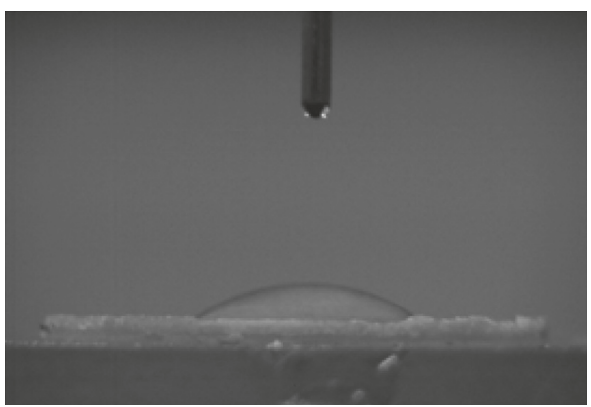

(b)

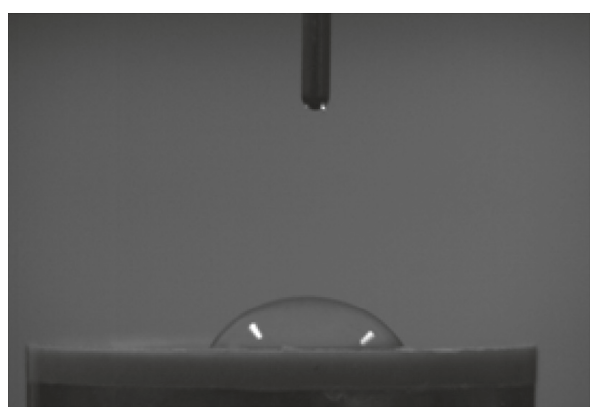

(d)

FIgUre 3: Contact angle analysis of MMT and $\mathrm{C}_{16}$ mim-MMT. (a) MMT; (b) 0\%; (c) 10\%; (d) 30\%.

the organic MMT is $41^{\circ}$, and the viscosity is $13.81 \mathrm{mPa} \cdot \mathrm{s}$. As the content of added water continues to increase, the contact angle and viscosity of the organic MMT also increase. At an added water content of $10 \%$, the organic MMT has a contact angle of $63^{\circ}$ and a viscosity of $68 \mathrm{mPa}$.s. As the water content continues to increase, the degree of organification of MMT increases as well. When the added water amount is 30\%, the contact angle of the organic MMT is $81.5^{\circ}$ with a viscosity of $152 \mathrm{mPa} \cdot \mathrm{s}$. The above results indicate that with the increase in the content of added water, the degree of organification of MMT continually increases.

As the content of added water increases, the $d_{001}$ value of organic MMT increases first and then decreases, and the maximum value is achieved at $10 \%$ added water. However, the contact angle and viscosity of organic MMT both increase as the external water content increases. These results indicate that the higher the content of external water, the higher the stacking degree of organic cations between the MMT layers and the greater the number of organic cations that are adsorbed onto the outer surface of MMT, that is, the degree of organification of MMT is enhanced.

\subsection{Influence Mechanism of External Water Amount on Organic MMT}

3.2.1. Effects of External Water on the Organic Intercalation Process. The XRD pattern can support the evidence that $\mathrm{C}_{16} \mathrm{mimCl}$ has been inserted into the interlayer spacing of MMT [28]. However, the specific insertion process of $\mathrm{C}_{16} \mathrm{mimCl}$ and the distribution pattern after intercalation can be studied using a molecular dynamics simulation. There is a significant difference in the interaction between $\mathrm{C}_{16} \mathrm{mimCl}$ and MMT in the environments with different water contents. When the content of external water is $30 \%$, cations such as $\mathrm{Na}^{+}$existing between MMT layers can diffuse out of the interlayer spacing of MMT into the aqueous solution. The originally charge-balanced MMT system then becomes imbalanced due to the loss of $\mathrm{Na}^{+}$. Since the MMT layer is negatively charged, the organic cations in the solution enter the interlayer spacings due to their electrostatic attraction to the MMT layer. Therefore, the interlayer spacing of the MMT gradually increases due to the entry of the organic cations (Figure 4). Water molecules play an 


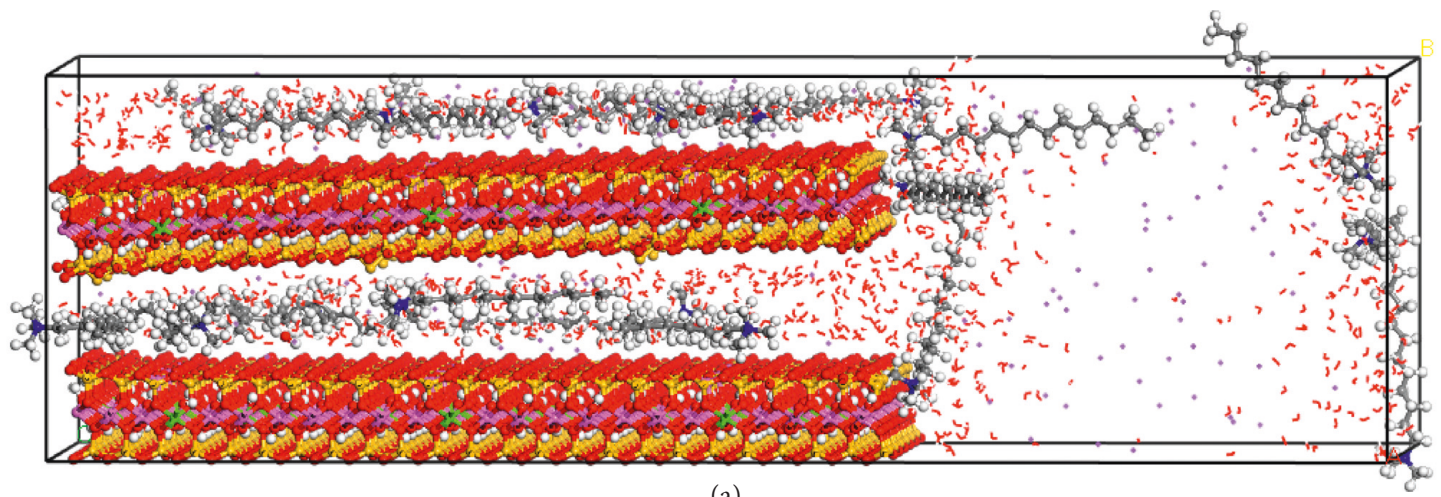

(a)

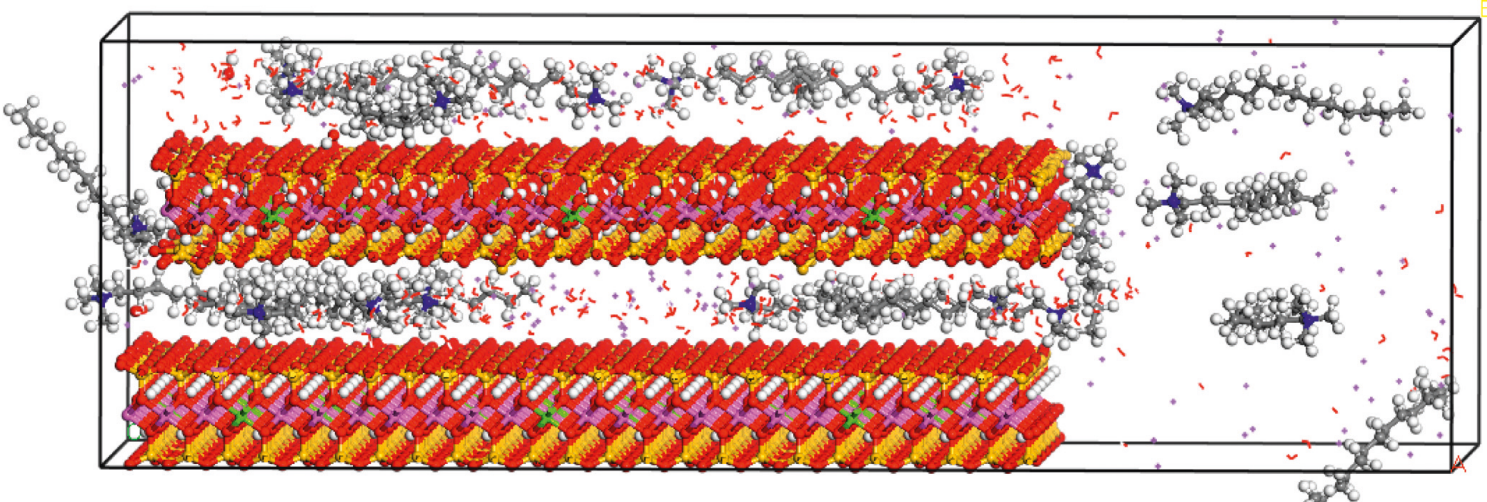

(b)

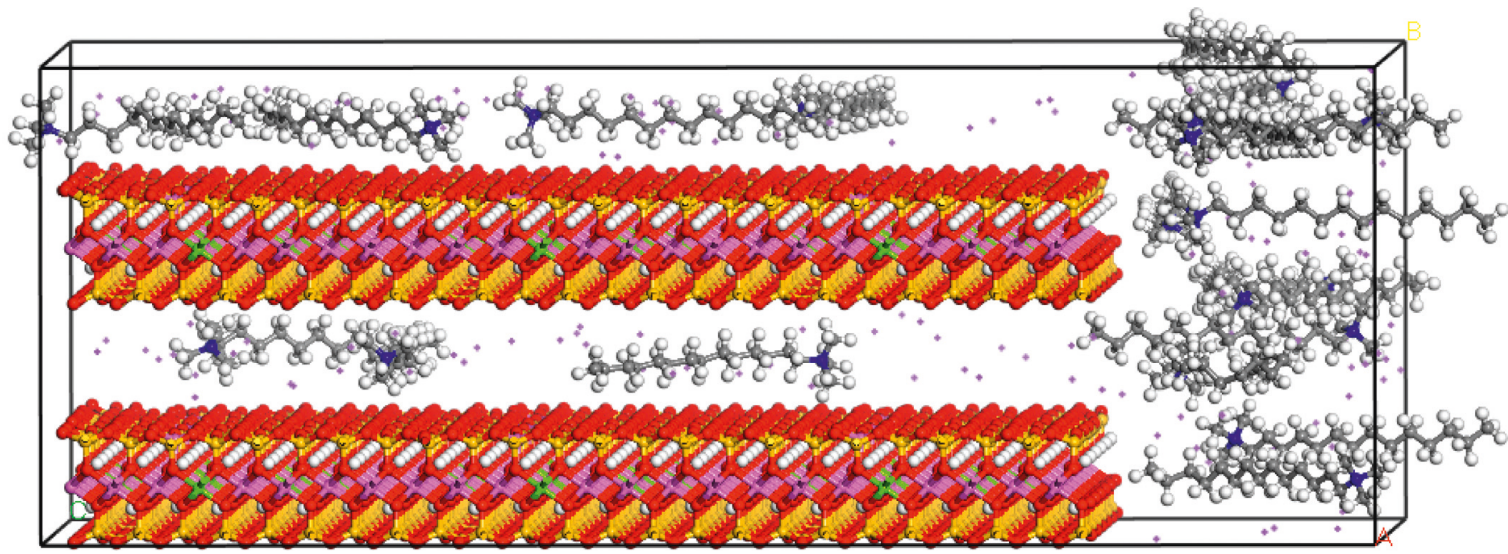

(c)

FIgURE 4: Molecular dynamic simulation of intercalation process. (a) $30 \%$; (b) $10 \%$; (c) $0 \%$.

important role in the intercalation process of organic cations $[29,30]$. When the content of added water is $30 \%$, a total of twenty $\mathrm{C}_{16} \mathrm{mimCl}$ molecules interact with MMT, fourteen of which intercalate between the MMT layers and six of which are adsorbed on the (100) plane of MMT (Figure 4(a)). Because of the higher water content, the positively charged $\mathrm{C}_{16} \mathrm{mim}^{+}$portion of the $\mathrm{C}_{16} \mathrm{mimCl}$ molecule interacts with MMT, while the $\mathrm{Cl}^{-}$portion diffuses into the aqueous solution or adsorbs onto the end planes of MMT, which promotes the adsorption of $\mathrm{C}_{16} \mathrm{mim}^{+}$on the MMT. When the content of added water is $10 \%$, the same twenty $\mathrm{C}_{16} \mathrm{mimCl}$ molecules interact with MMT, and fourteen of them intercalate between MMT layers, and two are adsorbed on the (100) plane of MMT (Figure 4(b)). The other four $\mathrm{C}_{16} \mathrm{mimCl}$ molecules do not interact with MMT because the diffusion process of the interlayer $\mathrm{Na}^{+}$cation is restricted at lower contents of water molecules. However, cation exchange is still possible when longer reaction times are used. When the applied water amount is $0 \%$, twenty $\mathrm{C}_{16} \mathrm{mimCl}$ molecules interact with MMT, but only seven molecules are inserted into the MMT interlayer, and the remaining $\mathrm{C}_{16} \mathrm{mimCl}$ molecules do not interact with MMT at all (Figure 4(c)). The above results indicate that external water during the intercalation process of MMT by $\mathrm{C}_{16} \mathrm{mimCl}$ acts an important medium which increases the diffusion rate of ions and also makes 


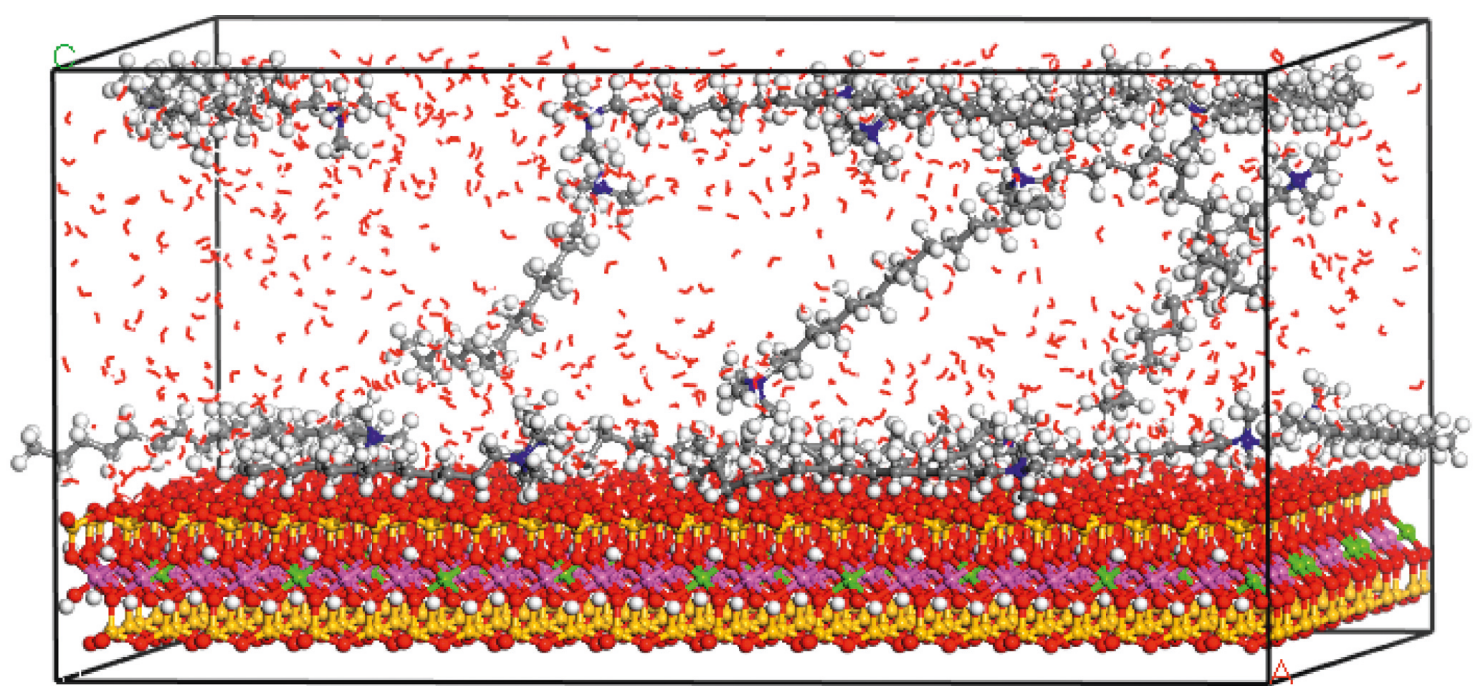

(a)

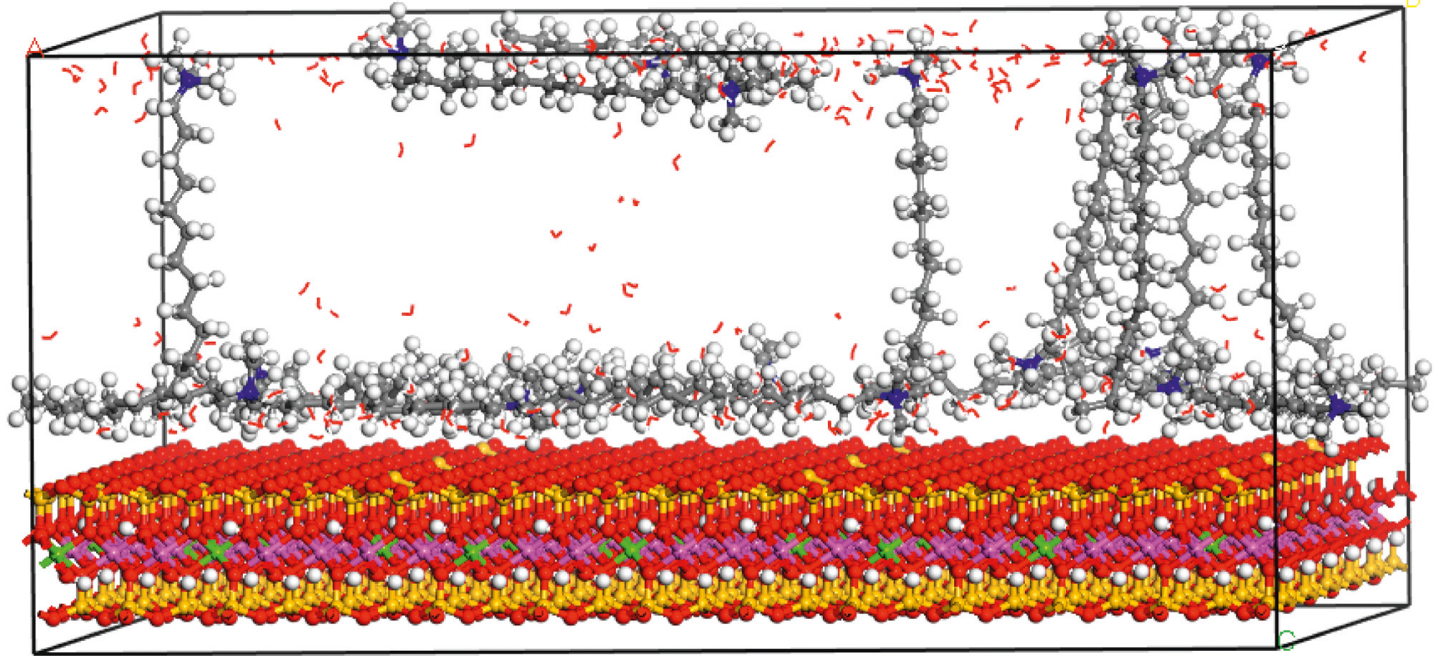

(b)

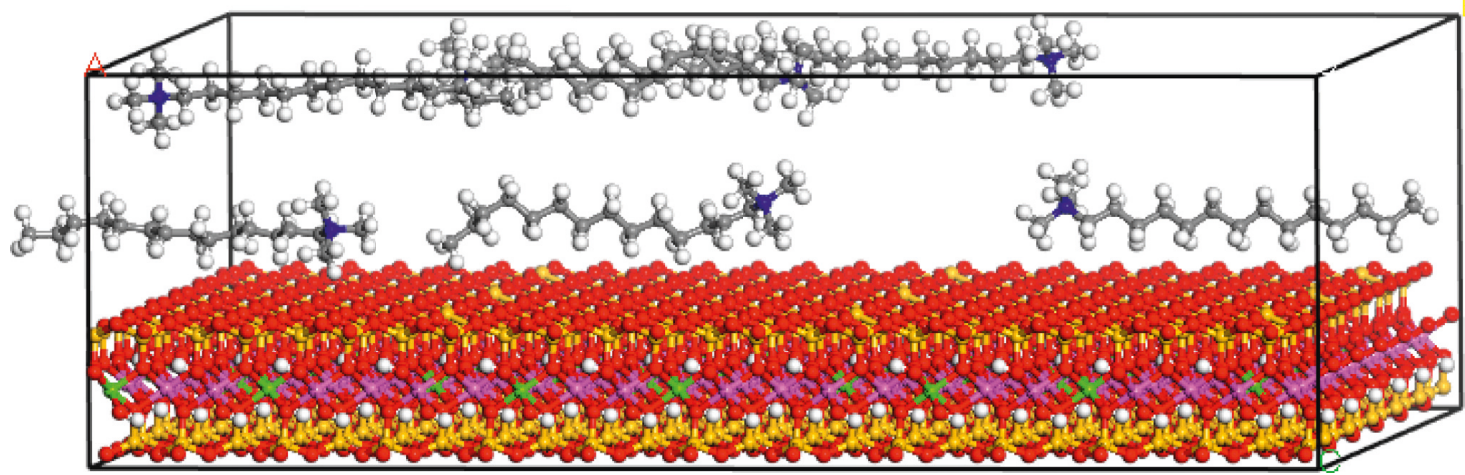

(c)

Figure 5: Molecular dynamic simulation of arrangement. (a) 30\%; (b) $10 \%$; (c) $0 \%$.

the structure of organic MMT more uniform and stable. In addition, the driving force of organic cations in the intercalation process of MMT not only includes electrostatic forces but also the hydrophobicity between organic cations and repulsion between ions $[18,31]$.
3.2.2. Effects of External Water on the Arrangement of Organic Matter in the Interlayer Spacing of MMT. After the organic cations are inserted between the MMT layers, the arrangement pattern between the layers may affect the performance of the organic MMT. The amount of external 
water not only affects the intercalation process of the organic cations but also the arrangement of the organic cations in the MMT interlayer spacing after intercalation [32, 33]. According to the simulation results in Section 3.2.1, when the applied water content was $30 \%$, ten $\left[\mathrm{C}_{16} \mathrm{mim}\right]^{+}$cations were inserted between the MMT layers, six of which were distributed parallel to the layer around the siloxane tetrahedron of MMT and four of which were inclined between two layers (Figure $5(\mathrm{a})$ ). The former six $\left[\mathrm{C}_{16} \mathrm{mim}\right]^{+}$cations have strong interactions with the layers due to electrostatic attractions while the latter four $\left[\mathrm{C}_{16} \mathrm{mim}\right]^{+}$cations have weaker interactions with the MMT layers, which together with the oblique arrangement, lead to the increase in the interlayer spacing of the organic MMT. When the external water content is $10 \%$, twelve $\mathrm{C}_{16} \mathrm{mim}^{+}$cations are inserted between the MMT layers. Among them, six $\mathrm{C}_{16} \mathrm{mim}^{+}$cations are distributed parallel to the layers around the MMT siloxane tetrahedron, and the remaining six $\mathrm{C}_{16} \mathrm{mim}^{+}$cations form micelles in the MMT interlayer, which increases the interlayer spacing of MMT (Figure 5(b)). $\mathrm{C}_{16} \mathrm{mim}^{+}$cations are arranged in the form of micelles in the MMT interlayer spacing, which reduced the stacking order, thus reducing the force between the MMT layers, which is an important method to exfoliate MMT [34-36]. When the added water volume is $0 \%$, five $\mathrm{C}_{16} \mathrm{mim}^{+}$cations are inserted into the MMT layers and are arranged around the silicon tetrahedron in a parallel lamellar structure, resulting in a smaller increase in the interlayer spacing of MMT (Figure 5(c)).

\section{Conclusions}

In this study, the effect of external water on the organic intercalation of MMT was discussed by adjusting the amount of added water. When MMT was modified by $\mathrm{C}_{16} \mathrm{mimCl}$ molecules, the organic modifier was inserted between the MMT layers and the organic MMT with a maximum interlayer spacing of $5.78 \mathrm{~nm}$ was successfully prepared. Increasing the content of external water expands the interlayer spacing of the organic MMT and intensifies the degree of organification, which leads to an enhancement in the order of stacking. The organically modified MMT presented obvious hydrophobicity from the contact angle measurements, and the thixotropic ring area became significantly larger, indicating enhanced rheological properties. When the content of external water was $10 \%$, the organic MMT with the largest interlayer spacing was prepared, and when the content was $30 \%$, the organic MMT with superior thixotropic properties was obtained. The results of this paper can provide theoretical support for the preparation of organic MMT and an investigation on the mechanism of organic intercalation.

\section{Data Availability}

The data used to support the findings of this study are available from the corresponding author upon request.

\section{Conflicts of Interest}

The authors declare that they have no conflicts of interest.

\section{Acknowledgments}

This research was jointly supported by the China Postdoctoral Science Foundation funded project (2018M631818) and the Doctoral Startup Foundation of Liaoning Province (20170520315).

\section{References}

[1] L. Fusova, "Modification of the structure of $\mathrm{Ca}-$ montmorillonite," GeoScience Engineering, vol. 4, no. 1, pp. 27-32, 2009.

[2] T. Vanorio, M. Prasad, and A. Nur, "Elastic properties of dry clay mineral aggregates, suspensions and sandstones," Geophysical Journal International, vol. 155, no. 1, pp. 319-326, 2003.

[3] R. Yi, G. Qiu, and X. Liu, "Rational synthetic strategy: from $\mathrm{ZnO}$ nanorods to $\mathrm{ZnS}$ nanotubes," Journal of Solid State Chemistry, vol. 182, no. 10, pp. 2791-2795, 2009.

[4] G. R. Whittell and I. Manners, "Metallopolymers: new multifunctional materials," Advanced Materials, vol. 19, no. 21 , pp. 3439-3468, 2007.

[5] W. Oueslati, H. Benrhaiem, B. Lanson, and A. Benhajamara, "Selectivity of Na-montmorillonite in relation with the concentration of bivalent cation $\left(\mathrm{Cu}^{2+}, \mathrm{Ca}^{2+}, \mathrm{Ni}^{2+}\right)$ by quantitative analysis of XRD patterns," Applied Clay Science, vol. 43, no. 2, pp. 224-227, 2009.

[6] J. M. Adams and R. W. McCabe, "Clay minerals as catalysts," Developments in Clay Science, vol. 1, pp. 541-581, 2006.

[7] S. Morodome and K. Kawamura, "In situ X-ray diffraction study of the swelling of montmorillonite as affected by exchangeable cations and temperature," Clays and Clay Minerals, vol. 59, no. 2, pp. 165-175, 2011.

[8] N. Khaorapapong, A. Ontam, and M. Ogawa, "Formation of $\mathrm{ZnS}$ and CdS in the interlayer spaces of montmorillonite," Applied Clay Science, vol. 50, no. 1, pp. 19-24, 2010.

[9] M. M. Hanczyc, S. M. Fujikawa, and J. M. Szostak, "Experimental models of primitive cellular compartments: encapsulation, growth, and division," Science, vol. 302, no. 5645, pp. 618-622, 2003.

[10] Q. H. Zeng, A. B. Yu, G. Q. Lu, and R. K. Standish, "Molecular dynamics simulation of Organic-Inorganic Nanocomposites: layering behavior and interlayer structure of organo clays," Chemistry of Materials, vol. 15, no. 25, pp. 4732-4738, 2003.

[11] T. D. K. Wungu, S. M. Aspera, M. Y. David, H. K. Dipojono, H. Nakanishi, and H. Kasai, "Absorption of lithium in montmorillonite: a density functional theory (DFT) study," Journal of Nanoscience and Nanotechnology, vol. 11, no. 4, pp. 2793-2801, 2011.

[12] F. Fang, H. J. Choi, and J. Joo, "Conducting polymer/clay nano composites and their applications," Journal of Nanoscience and Nanotechnology, vol. 8, no. 4, pp. 1559-1581, 2008.

[13] G. Janowska, T. Mikolajczyk, and M. Olejnik, "Effect of montmorillonite content and the type of its modifier on the thermal properties and flammability of polyimideamide nanocomposite fibers," Journal of Thermal Analysis and Calorimetry, vol. 92, no. 2, pp. 495-503, 2008.

[14] H. L. Lin, H. L. Chang, T. Y. Juang et al., "Nonlinear optical, poly(amide-imide)-clay nanocomposites comprising an azobenzene moiety synthesised via sequential selfrepetitive reaction," Dyes and Pigments, vol. 82, no. 1, pp. 76-83, 2009.

[15] S. Yoshimoto, F. Ohashi, and T. Kameyama, "X-ray diffraction studies of intercalation compounds prepared from aniline salts and montmorillonite by a mechanochemical 
processing," Solid State Communications, vol. 136, no. 5, pp. 251-256, 2005.

[16] S. Pavlidou and C. D. Papaspyrides, "A review on polymerlayered silicate nanocomposites," Progress in Polymer Science, vol. 33, no. 12, pp. 1119-1198, 2008.

[17] F. Román, S. Montserrat, and J. M. Hutchinson, "On the effect of montmorillonite in curing reaction of epoxy nanocomposites," Journal of Thermal Analysis and Calorimetry, vol. 87, no. 1, pp. 113-118, 2007.

[18] L. M. Wu, C. X. Yang, L. F. Mei, F. X. Qin, L. B. Liao, and G. C. Lv, "Microstructure of different chain length ionic liquids intercalated into montmorillonite: a molecular dynamics study," Applied Clay Science, vol. 99, pp. 266-274, 2014.

[19] K. Morishige, H. Yasunaga, R. Denoyel, and V. Wernert, "Pore-blocking-controlled freezing of water in Cagelike Pores of KIT-5," Journal of Physical Chemistry C, vol. 111, no. 26, pp. 9488-9495, 2007.

[20] A. H. Janssen, H. Talsma, M. J. van Steenbergen, and K. P. de Jong, "Homogeneous nucleation of water in mesoporous zeolite cavities," Langmuir, vol. 20, no. 1, pp. 41-45, 2004.

[21] H. R. J. Pruppacher, "A new look at homogeneous ice nucleation in supercooled water drops," Journal of the Atmospheric Sciences, vol. 52, no. 11, pp. 1924-1933, 1995.

[22] P. Lanthong, R. Nuisin, and S. Kiatkamjornwong, "Graft copolymerization, and degradation of cassava starch-gacrylamide/itaconic acid superabsorbents," Carbohydrate Polymers, vol. 66, no. 2, pp. 229-245, 2006.

[23] J. Zhang, H. Chen, and A. Wang, "Study on superabsorbent composite. III. Swelling behaviors of polyacrylamide/ attapulgite composite based on acidified attapulgite and organo-attapulgite," European Polymer Journal, vol. 41, no. 10, pp. 2434-2442, 2005.

[24] N. Seetapan, N. Anasuwan, and S. Kiatkamjornwong, "Superabsorbent polymer nanocomposites with surfactant- or acid-modified Ca-montmorillonite: synthesis and water absorbency," Journal of Polymer Research, vol. 22, no. 3, p. 31, 2015.

[25] R. L. Frost, Q. Zhou, H. He, and Y. Xi, "An infrared study of adsorption of paranitrophenol on mono-, di-and tri-alkyl surfactant intercalated organoclays," Spectrochimica Acta Part A: Molecular and Biomolecular Spectroscopy, vol. 69, no. 1, pp. 239-244, 2008.

[26] K. Suga and J. F. Rusling, "Structural characterization of surfactant and clay-surfactant films of micrometer thickness by FT-IR spectroscopy," Langmuir, vol. 9, no. 12, pp. 36493655, 1993.

[27] N. Venkataraman and S. Vasudevan, "Characterization of alkyl chain conformation in an intercalated cationic lipid bilayer by IR spectroscopy," Journal of Physical Chemistry B, vol. 106, no. 32, pp. 7766-7773, 2002.

[28] T. J. Tambach, P. G. Bolhuis, E. J. M. Hensen, and B. Smit, "Hysteresis in clay swelling induced by hydrogen bonding: accurate prediction of swelling states," Langmuir, vol. 22, no. 3, pp. 1223-1234, 2006.

[29] X. Liu and X. Lu, "A thermodynamic understanding of clayswelling inhibition of interlayer potassium ion," Angewandte Chemie International Edition, vol. 45, no. 38, pp. 6300-6303, 2006.

[30] X. Liu, X. Lu, R. Wang, and H. Zhou, "Effects of layer-charge distribution on the thermodynamic and microscopic properties of Cs-smectite," Geochim Cosmochim Acta, vol. 72, no. 7, pp. 1837-1847, 2008.
[31] L. M. Wu, L. B. Liao, and G. C. Lv, "Influence of interlayer cations on organic intercalation of montmorillonite," Journal of Colloid and Interface Science, vol. 454, pp. 1-7, 2015.

[32] R. T. Cygan, J. J. Liang, and A. G. Kalinichev, "Molecular models of hydroxide, oxyhydroxide, and clay phases and the development of a general force field," The Journal of Physical Chemistry B, vol. 108, no. 4, pp. 1255-1266, 2004.

[33] Y. Zhang, Y. F. Meng, H. B. Liu, and M. L. Yang, "Firstprinciples study of water desorption from montmorillonite surface," Journal of Molecular Modeling, vol. 22, no. 5, p. 105, 2016.

[34] Z. Li, P. H. Chang, J. S. Jean, and W. T. Jiang, "Interaction between tetracycline and smectite in aqueous solution," Journal of Colloid and Interface Science, vol. 341, no. 2, pp. 311-319, 2010.

[35] C. J. Wang, Z. Li, W. T. Jiang, J. S. Jean, and C. C. Liu, "Cation exchange interaction between antibiotic ciprofloxacin and montmorillonite," Journal of Hazardous Materials, vol. 183, no. 1-3, pp. 309-314, 2010.

[36] Q. Wu, Z. Li, H. Hong, K. Yin, and L. Tie, "Adsorption and intercalation of ciprofloxacin on montmorillonite," Applied Clay Science, vol. 50, no. 2, pp. 204-211, 2010. 


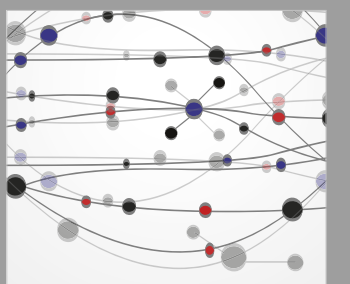

The Scientific World Journal
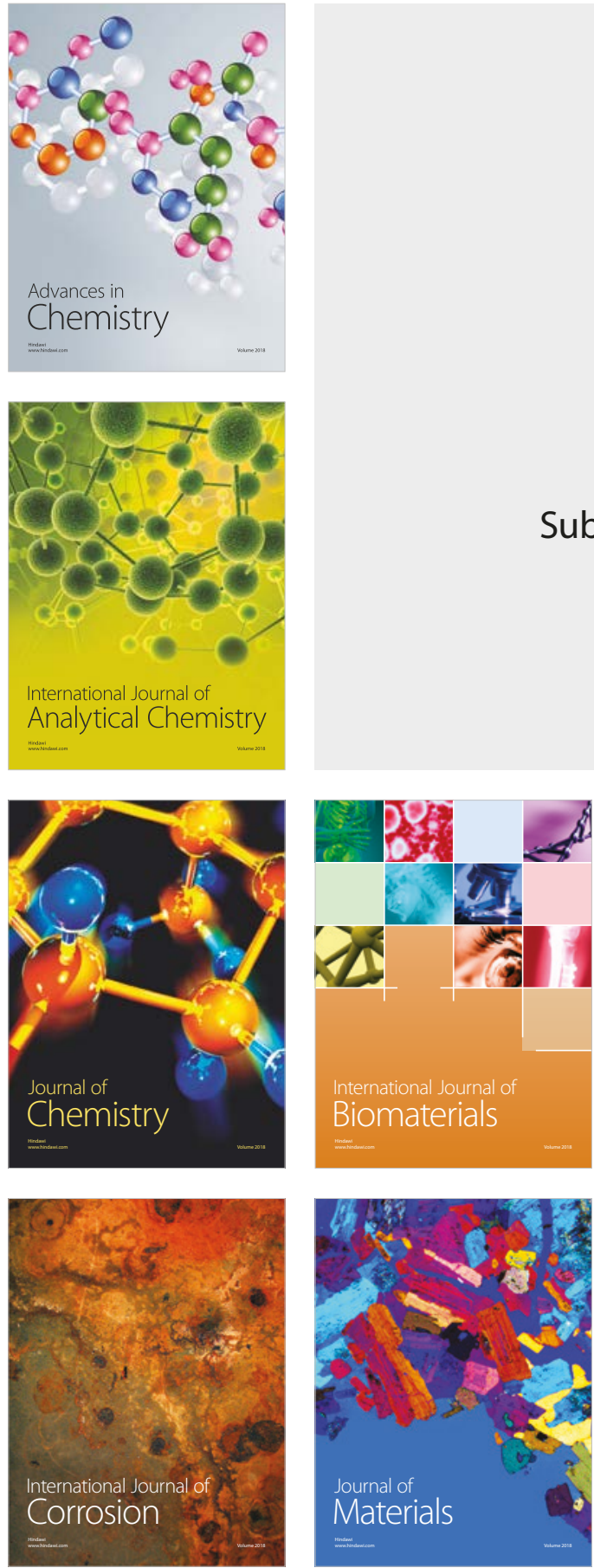

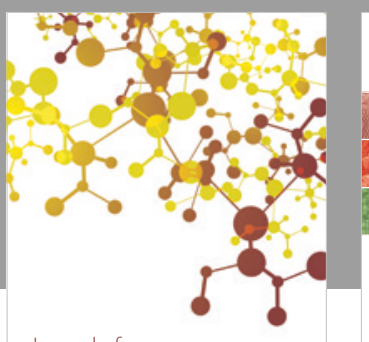

Journal of

Applied Chemistry
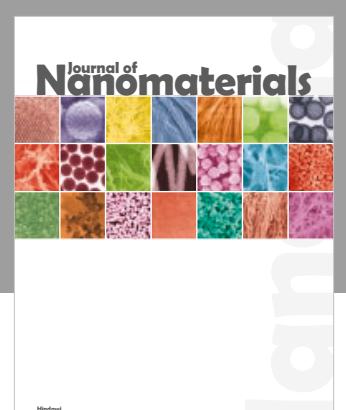

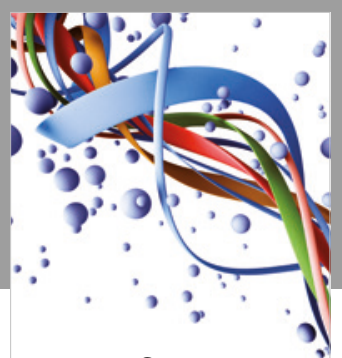

Scientifica

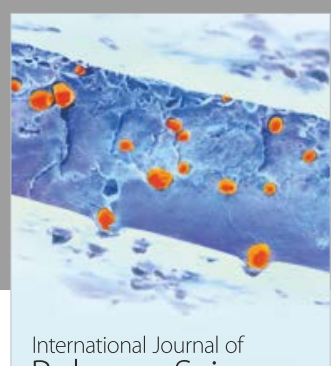

Polymer Science

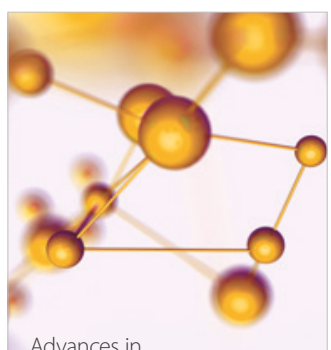

Physical Chemistry
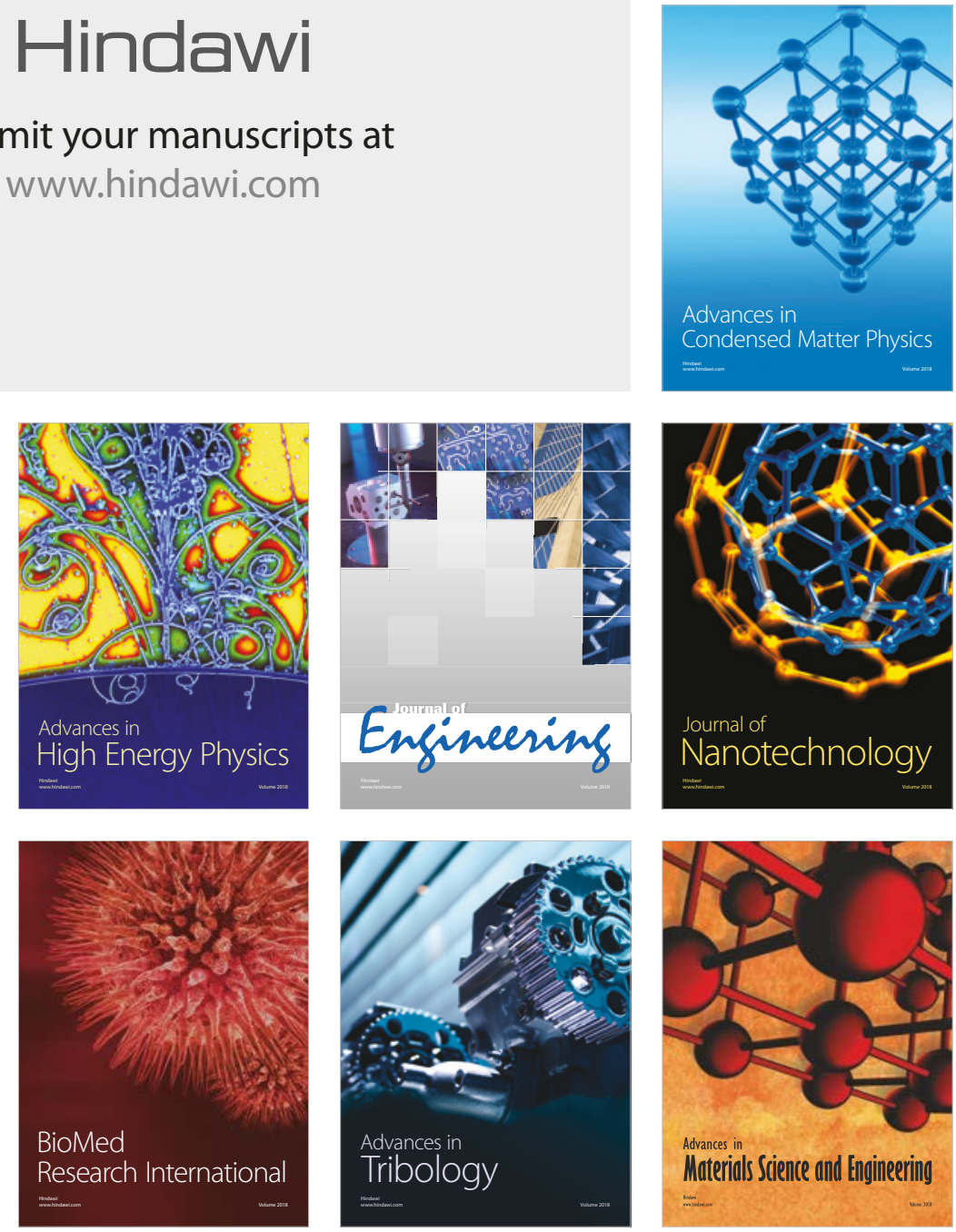